\title{
VON WILLEBRAND DISEASE WITH SEVERE MENORRHAGIA- HOW WE HANDLED: A CASE REPORT
}

\author{
Yelamanchili Anuragamayi ${ }^{1}$, Cherukuri Karuna Kumari², D. Rajya Lakshmi ${ }^{3}$, Prasanna ${ }^{4}$
}

\section{HOW TO CITE THIS ARTICLE:}

Yelamanchili Anuragamayi, Cherukuri Karuna Kumari, D. Rajya Lakshmi, Prasanna. "Von Willebrand Disease with severe Menorrhagia-How we handled: A Case Report". Journal of Evolution of Medical and Dental Sciences 2014; Vol. 3, Issue 30, July28; Page: 8411-8413, DOI: 10.14260/jemds/2014/3062

INTRODUCTION: VWD is named after Erik Adolf Von Willebrand, a Finnish pediatrician who first described the disease in 1926. Von Willebrand disease is the most common hereditary coagulation abnormality described in humans, although it can also be acquired as a result of other medical conditions. It arises from a qualitative or quantitative deficiency of Von Willebrand factor (VWF), a multimeric protein that is required for platelet adhesion.

There are three forms of VWD: VWD Type-I, Type-II, Type-III. Within the three inherited types of VWD there are various sub-types. ${ }^{1}$ VWD Type- 1 is the most common type of the disorder ${ }^{2}$ and those that have it are typically asymptomatic or may experience mild symptoms such as nose bleeds although it may be severe in some cases. There are various factors that affect the presentation and severity of symptoms of VWD such as blood type. ${ }^{3}$

CASE REPORT: T. Pavani, 28years old woman a graduate came to our institute with menorrhagic cycles since menarche. There was history of bleeding diathesis, bleeding gums, macular patches all over the body. History of prolonged bleeding from wound site seven with trivial injury with history of epistaxis was also present. She attended Government General Hospital with bleeding diathesis. Multiple 0 positive blood transfusions were given till menarche.

She attained menarche at 12years, thereafter she used to menstruate for 3-4 months continuously with a gap of 15 days. Episodes were heavy requiring 15 - 20 pads a day. At menarche, she had continuous bleeding for 3-4 months came to Government General Hospital. Due to uncontrolled menorrhagia, 4 units blood was transfused, referred to higher centers like NIMS, Hyderabad, Bombay, CMC, Vellore in 2007.

There she was diagnosed as VWD Type - III and Factor VIII transfused (4 vials). In 2008 she came to Government General Hospital again with menorrhagia. She was managed with OC pills, Danazol and it was controlled for some extent but again she came with menorrhagia and severe anemia. In 2010 radiation was given for 10 days in a dose of 1 dose/day to create artificial menopause. Radiation stopped in view of radiation induced malignancy risk.

Menorrhagia was controlled for 3 years after radiation. In 2013 she was again admitted in view of menorrhagia with severe anemia. Anemia treated with blood transfusions, Mirena, an IUCD inserted under short general anesthesia in October 2013. After that moderate amount of bleeding per vagina occurred for one month and after that she developed amenorrhea which is continuing till now.

DISCUSSION: VWD is a rare bleeding disorder seen most often in women whose bleeding tendency shows during menstruation. Our patient is having type-III VWD which is the most severe form ${ }^{2}$ of VWD with clinical manifestation of life threatening external and internal hemorrhage. The 
inheritance of Type-III VWD is autosomal recessive. ${ }^{3}$ Our patient is having bleeding diathesis since childhood and she presented with severe form during menstruation.

Her blood group is 0 positive where VWD is severe with 0 positive blood group. Our patient was treated with estrogen, progesterone and danazol but the effect was temporary and failed to decrease the menstrual flow. Hence, surgery was thought to secure the problem. Hysterectomy can be planned by keeping factor VIII concentrates, but in our institute Factor VIII is not available and also patient is not willing to go for higher centers.

We decided to insert Mirena IUCD in order to create Amenorrhea. As she is unmarried special consent was taken and also informed that it needs to be replaced after 5 years. We advised her to come for regular follow up and she is coming regularly and her general condition is good now.

Mirena belongs to third generation IUCD and releases 20 micro grams of LNG per day and contains 52milli grams LNG. It acts directly on endometrium and suppress it with less systemic side effects $^{4}$. It reduces blood loss in $97 \%$ cases as effective as endometrial ablation done hysteroscopically.

It takes three months before it shows decrease in bleeding, in 20 to $25 \%$ of cases amenorrhea occurs. In our patient it was found effective in reducing the menstrual flow in the subsequent cycles and menstruation completely stopped afterwards. Now her general condition is improved.

CONCLUSION: Out of all the medical methods, OC pills, danazol, mirena IUCD is effective in controlling menorrhagia in bleeding disorders like VWD. It is also a safe procedure and safe alternative to hysterectomy procedure.

\section{REFERENCES:}

1. Sadler JE. "A revised classification of von Willebrand disease. For the Subcommittee on von Willebrand Factor of the Scientific and Standardization Committee of the International Society on Thrombosis and Haemostasis". Thromb. Haemost.1994; 71 (4): 520-5. PMID 8052974.

2. Harrison's text book of Internal Medicine, Chapter 110, 17th edition, Vol-1, 2008, Pg.723-724.

3. "Molecular basis of von Willebrand disease and its clinical implications". Haematologica; 2004; 89 (9): 1036. PMID 15377463.

4. Williams Gynaecology. Abnormal uterine bleeding, Chapter 8; 2nd edition, Page: 238.

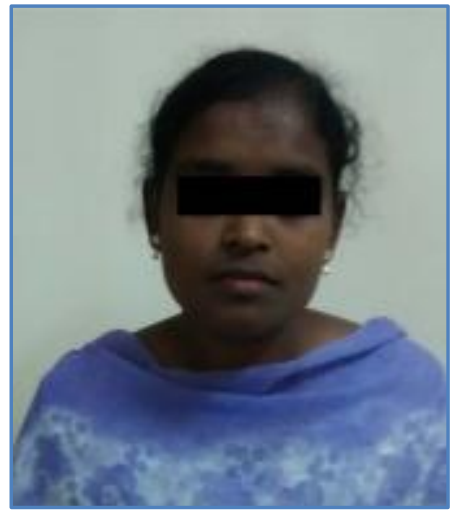

Fig. 1

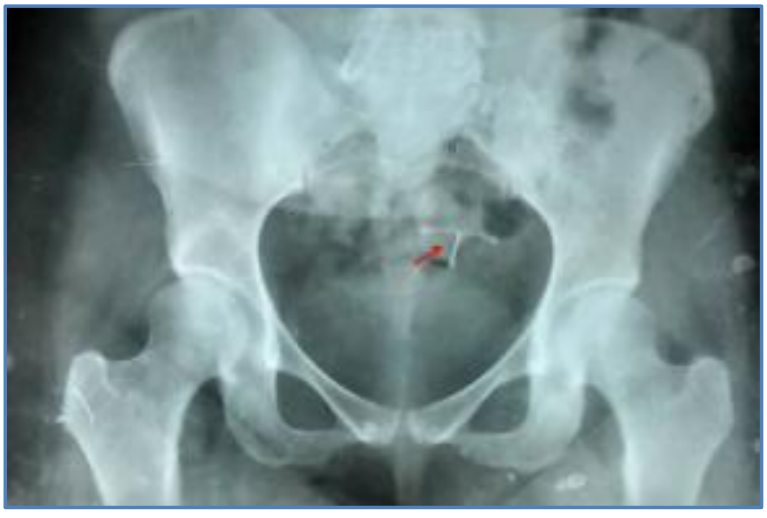

Fig. 2: X-ray 


\section{CASE REPORT}

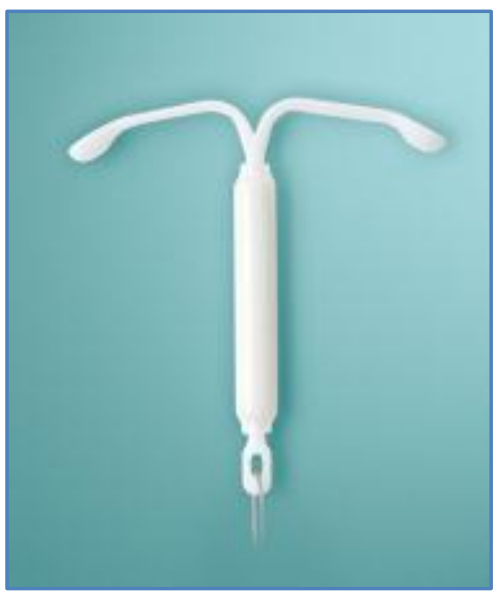

Fig. 3: Mirena

\section{AUTHORS:}

1. Yelamanchili Anuragamayi

2. Cherukuri Karuna Kumari

3. D. Rajya Lakshmi

4. Prasanna

\section{PARTICULARS OF CONTRIBUTORS:}

1. Assistant Professor, Department of Obstetrics and Gynaecology, NTR University of Health Sciences.

2. Assistant Professor, Department of Obstetrics and Gynaecology, NTR University of Health Sciences.

3. Professor and HOD, Department of Obstetrics and Gynaecology, NTR University of Health Sciences.

4. Post Graduate, Department of Obstetrics and Gynaecology, NTR University of Health Sciences.

\section{NAME ADDRESS EMAIL ID OF THE CORRESPONDING AUTHOR:}

Dr. Yelamanchili Anuragamayi, A5-Quarter,

RMC Campus,

Pithapuram Road,

Kakinada-533003.

Email: anuragamayi.y@gmail.com

Date of Submission: 14/07/2014.

Date of Peer Review: 15/07/2014.

Date of Acceptance: 21/07/2014.

Date of Publishing: 24/07/2014. 